\title{
Philippe Chardin (dir.), Marjorie Rousseau (dir.), L'écrivain et son critique: une fratrie problématique
}

\section{Roberta Sapino}

\section{(2) OpenEdition}

1 Journals

\section{Edizione digitale}

URL: http://journals.openedition.org/studifrancesi/1684

DOI: 10.4000/studifrancesi. 1684

ISSN: 2421-5856

Editore

Rosenberg \& Sellier

\section{Edizione cartacea}

Data di pubblicazione: 1 novembre 2014

Paginazione: 656-657

ISSN: 0039-2944

\section{Notizia bibliografica digitale}

Roberta Sapino, «Philippe Chardin (dir.), Marjorie Rousseau (dir.), L'écrivain et son critique: une fratrie problématique », Studi Francesi [Online], 174 (LVIII | III) | 2014, online dal 01 novembre 2014, consultato il 18 septembre 2020. URL : http://journals.openedition.org/studifrancesi/1684 ; DOI : https://doi.org/ 10.4000/studifrancesi. 1684

Questo documento è stato generato automaticamente il 18 settembre 2020.

\section{(c)}

Studi Francesi è distribuita con Licenza Creative Commons Attribuzione - Non commerciale - Non opere derivate 4.0 Internazionale. 


\title{
Philippe Chardin (dir.), Marjorie Rousseau (dir.), L'écrivain et son critique: une fratrie problématique
}

\author{
Roberta Sapino
}

\section{NOTIZIA}

PHILIPPE CHARDIN (dir.), MARJORIE ROUSSEAU (dir.), MAGALI RENOUf, L'écrivain et son critique: une fratrie problématique, Paris, Éditions Kimé, 2014, pp. 567.

1 Il volume, che raccoglie gli atti del XXXVIII Congrès de La Société Française de Littérature Générale et Comparée Tours-Orléans tenutosi a Tours nell'ottobre 2012, si propone di esplorare le diverse sfaccettature della relazione ambivalente che lega pratica letteraria e attività critica.

2 «Il nous a semblé que l'écrivain et son critique étaient en fait des doubles», scrivono Philippe CHARDIN e Marjorie ROUSSEAU nell'introduzione (pp. 7-36): alla base delle ricerche presentate vi è il postulato che scrittore e critico possano essere considerati poli indissolubili in una relazione di rivalità e fratellanza in costante rielaborazione, fonte di conflitti e stimoli, permeabilità e influenze più o meno dichiarate, talvolta di inversione dei ruoli.

3 Un rapido sguardo alla table des matières permette di cogliere la minuziosa organizzazione della miscellanea: in una cornice composta da tre contributi di natura teorica (raccolti sotto il cappello «Réflexions générales») dedicati rispettivamente alla critique créatrice teorizzata dal Gruppo di Ginevra, a un'analisi comparativa dei diversi rapporti che possono intercorrere tra $\mathrm{i}$ due poli in questione e alla posizione flaubertiana rispetto alla critica letteraria, si articola un corpus di quarantuno interventi che, alternando punti di vista ora cronologici, ora generici, ora geografici, ben restituisce la complessità e la fecondità del campo di ricerca. 
4 La prima sezione del volume, intitolata «Approches chronologiques et génériques» (pp. 51-242), si apre con un gruppo di contributi dedicati ai secoli xvIII e xIx, e al xx in quanto "lettore" del precedente. Ne risulta un percorso che inizia con la contraddittoria postura voltairiana rispetto a Milton e Shakespeare per arrivare a Jean Prévost e Tomasi di Lampedusa lettori di Stendhal, e dal quale emerge l'importanza di accostarsi al discorso critico avendo cura di considerarlo all'interno di un contesto contemporaneamente estetico, ideologico e politico, influenzato talvolta da pregiudizi collettivi o personali, e caratterizzato da reinterpretazioni, appropriazioni e prese di distanze non sempre programmatiche. Nella seconda parte della sezione la finestra temporale si allarga fino a includere anche il Seicento, e il taglio critico si focalizza sullo sviluppo e la ridiscussione dei generi del teatro e della poesia: se il primo si presenta tradizionalmente come luogo di parola e scambio, talvolta di scontro, meno evidente è forse osservare casi in cui i limiti generici tra pratica critica e poetica sono messi radicalmente alla prova.

5 La seconda sezione, «De quelques effets sur la création littéraire des modèles théoriques, des critiques et des censures» (pp. 243-354), si rivolge principalmente al genere romanzesco e raccoglie interventi che mettono in luce le diverse reazioni di autori novecenteschi agli appunti della critica: reazioni accomunate da una certa volontà di resistenza, ma che rivelano la necessità per ognuno dei due ambiti di concepirsi in relazione all'altro. Particolarmente interessante la seconda parte della sezione, dedicata alla censura intesa un po' provocatoriamente come forma estrema ed estremista di critica letteraria, presa di posizione ideologica che alcuni scrittori e critici contribuirono - paradossalmente e in modo più o meno intenzionale - a indirizzare.

«L'écrivain et le critique; le même et l'autre» è il titolo della terza e ultima sezione (pp. 355-512), che si addentra in quello spazio di confine propizio allo sviluppo di forme ibride di critica e creazione, laddove lo specialista universitario può farsi narratore e il récit può inglobare modalità e soggetti tipicamente appartenenti al versante opposto. Focalizzati principalmente sugli ultimi due secoli ma estesi in buona parte a letterature che esulano dall'hexagone, gli interventi sono organizzati secondo tre assi tematici: "critique et hybridité", "mise en fiction de la critique" e "la littérature comparée mène à tout, même à la littérature".

7 In calce, un indice dei nomi e uno delle opere citate consentono di muoversi agilmente tra i contributi, facilitando letture incrociate che la varietà dei testi presi in analisi e delle posture teoriche adottate non può che suggerire. 